\title{
El regionalismo en la arquitectura religiosa de posguerra en Asturias: el proyecto neoprerrománico para la reconstrucción de la iglesia parroquial de La Felguera, Langreo
}

Noelia Fernández García

RESUMEN:

Tras el establecimiento de la dictadura en la España de la posguerra, la arquitectura se vio supeditada a sus intereses políticos e ideológicos, hecho que unido al aislamiento del país desembocó en la recuperación de las formas constructivas anteriores y, por ende, de los historicismos. El proceso de reconstrucción de la arquitectura religiosa estuvo marcado, en gran medida, por la línea regionalista o casticista, motivo por el que, en el caso del Principado de Asturias, destaca la recuperación del prerrománico asturiano. El primer proyecto para la reconstrucción de la iglesia parroquial de Santa Eulalia de Turiellos se presenta como el ejemplo más patente del uso del neo-prerrománico para estas arquitecturas, a pesar de no haber llegado a materializarse.

PALABRAS CLAVE:

Franquismo, reconstrucción, Langreo, La Felguera, José Ramón del Valle Lecue, neoprerrománico

\section{ABSTRACT:}

After the establishment of Franco's dictatorship in Spain, architecture was strongly controlled by the political and ideological state interests. This fact, joined to the international isolation of the country, led to the recovery of historical styles. Religious architecture reconstruction process was defined, mostly, by regionalisms and this is the reason why asturian pre-romanesque style was recovered in the Princedown of Asturias. The first project made for the reconstruction of Santa Eulalia de Turiellos parish church is a great example of the use given to pre-romanesque style in this architectures, although it wasn't built finally.

\section{KEYWORDS:}

Franco’s dictatorship, reconstruction, Langreo, La Felguera, José Ramón del Valle Lecue, neopre-romanesque

La presente investigación se realiza en el marco de la tesis doctoral La arquitectura religiosa del franquismo en Asturias: de la reconstrucción a la renovación, vinculada al proyecto de investigación Los arquitectos restauradores en la España del franquismo. De la continuidad de la ley de 1933 a la recepción de la teoría europea, ref. HAR2015-68109-P. Financiado por el Ministerio de Economía y Competitividad (Gobierno de España) y los Fondos FEDER. 


\section{Posguerra, Autarquía y reconstrucción en Asturias}

Los primeros años después del final de la guerra estuvieron fuertemente marcados por la situación económica en la que el país se encontraba inmerso. Las destrucciones y pérdidas causadas por la guerra se vieron incrementadas por las malas cosechas, la escasez de viviendas y la insalubridad ${ }^{1}$. Por otro lado, las medidas autárquicas tomadas por el régimen provocaron importantes transformaciones, causando la vuelta de muchos al campo ${ }^{2}$. Esta situación fue aprovechada dentro de los valores ideológicos de los vencedores, los cuales potenciaron el mundo rural en contraposición a lo urbano, mitificando al campesinado de vida austera y sencilla cuyos pequeños núcleos poblacionales habían sido de gran ayuda para la victoria del nuevo Régimen ${ }^{3}$.

Estos cambios afectarían económica y socialmente a toda España, sin embargo, la situación de Asturias fue relativamente privilegiada dentro del contexto nacional ${ }^{4}$ : en la década de 1940, el sector industrial asturiano, en el que contemplamos minería y siderurgia, se vería favorecido debido a la coyuntura internacional, marcada por el desarrollo de la Segunda Guerra Mundial y la reconstrucción posterior que hubo de llevarse a cabo ${ }^{5}$. Así, las zonas industriales, como la cuenca del Nalón y Langreo dentro de ella, prosperaron debido a su creciente actividad, con el consiguiente aumento demográfico, hecho que resultó clave en la reconstrucción de estas zonas durante la posguerra y que influyó claramente en la construcción de la iglesia parroquial que aquí trataremos, al igual que con muchos otros ejemplos en toda la región.

En estos momentos, la Iglesia católica, junto a la Falange y el Ejército, supuso uno de los apoyos de mayor importancia para el Régimen del 18 de julio debido a los ataques que había

RODRÍGUEZ MUÑOZ, Javier, Asturias bajo el franquismo, Oviedo, La Nueva España, 2010, p. 9.

2 RODRÍGUEZ MUÑOZ, Javier, Asturias bajo..., opus cit., p. 9.

TREVIÑO CARRILLO, Bárbara, "La utopía ruralista del primer franquismo en los planes de reconstrucción de la posguerra", en línea, http://hispanismo.cervantes.es/ documentos/trevino.pdf

4 RODRÍGUEZ MUÑOZ, Javier, Asturias bajo..., opus cit., p. 9.

5 RUIZ, David, “Guerra Civil y Franquismo (1936-1975)” en Asturias Contemporánea 1808-1975, Madrid, Editorial siglo veintiuno de España, 1981, p. 129. sufrido durante la guerra ${ }^{6}$; asimismo, con su favor, se pretendía conseguir el apoyo del Vaticano y mitigar la hostilidad de las democracias ${ }^{7}$, maniobra que respondía, principalmente, a la necesidad de distanciamiento de la imagen de los regímenes autoritarios nazi y fascista. Por ello, la Iglesia estuvo involucrada en la mayoría de aspectos relativos al régimen franquista, también en la arquitectura, tal como se manifestó en los puntos de la Falange, concretamente en el número 25, que serían convertidos en la norma pragmática del Estado ${ }^{8}$ :

\footnotetext{
"Nuestro movimiento incorpora el sentido católico- de gloriosa tradición y predominante en España- a la reconstrucción nacional." 9
}

Como se ha mencionado anteriormente, las destrucciones causadas durante la guerra fueron muy numerosas y el Estado debía enfrentarse a la restauración o reconstrucción de numerosos monumentos de vital importancia. Para tal propósito ya en enero de 1938, se creó el Servicio de Regiones Devastadas y Reparaciones, perteneciente al Ministerio del Interior, cuya denominación cambió a Ministerio de la Gobernación poco después ${ }^{10}$. El SRDR se dividió en siete comisiones repartidas por la geografía española, constituyéndose la sede de la zona cantábrica en Oviedo, hecho que resultaría de vital importancia para las arquitecturas del primer franquismo en la región, pues están marcadas por los criterios de este organismo en gran medida.

Por otro lado, en 1941, se creó la Junta Nacional de Reconstrucción de Templos $\mathrm{Pa}-$ rroquiales, un nuevo organismo también dependiente del Ministerio de Gobernación y, por tanto, de la Dirección General de Regiones De-

$6 \quad$ AA.VV, Asturias. El siglo XX en imágenes..., opus cit., , p. 30.

JOVER ZAMORA, José María (dir.), “La época de Franco (1939-1975). Política. Ejército. Iglesia. Economía y administración”. Enciclopedia Historia de España Menéndez Pidal, Madrid, Espasa Calpe, 1996, p. 49.

8 MORADIELLOS, Enrique, La España de Franco (19391975). Política y Sociedad, Madrid, Editorial Síntesis, 2000, p. 286

9 Véase Doctrina e Historia de la Revolución Nacional Española, en La España de Franco..., opus cit., p. 286.

10 MAS TORRECILLAS, Vicente Javier, Arquitectura social y Estado entre 1939 y 1957. La Dirección General de Regiones Devastadas. (Tesis doctoral). UNED, 2008, p. 87. 
vastadas, que se encargaría de la recuperación del patrimonio eclesiástico y de proporcionar nuevos espacios de culto, en entornos tanto rurales como urbanos, tras los ataques anticlericales sufridos durante la guerra ${ }^{11}$, focalizando aún más las labores de restauración y reconstrucción.

Esta nueva situación política demandaba una nueva arquitectura que identificase a España y mostrase la nueva situación en que el país se encontraba; no obstante, la existencia de un estilo arquitectónico propio dentro del franquismo ha sido ampliamente discutida, aunque lo que resulta innegable la existencia de una "unidad de estilo"12. La búsqueda de éste, que debía concordar con el espíritu del Régimen, se hacía más que necesaria, pues debía ser ejemplo de la idea de "identidad nacional" ${ }^{13}$, mostrando la idea de unidad, el nacionalismo radical, la acción directora y rectora del Estado sobre la cultura, junto con la crítica a la vanguardia y el arte como instrumento de propaganda ${ }^{14}$. Para la creación de ese estilo, el Régimen se propuso establecer un programa estético oficial basado en los fascismos europeos y el tradicionalismo autóctono ${ }^{15}$. Tales intereses sobre lo que debía transmitir la arquitectura nos indican que, en estos momentos, se pretendieron recuperar los ideales y valores de etapas anteriores de la historia de España correspondientes con sus grandes momentos: la Reconquista, el reinado de los Reyes Católicos y el Imperio de Felipe II $^{16}$. El Régimen, cuyo pensamiento político estaba inspirado en el "neoimperialismo" ${ }^{17}$, pretendía identificarse con las gloriosas etapas de España y demostrar, así, que su mayor pretensión era

11 MAS TORRECILLAS, Vicente Javier, Arquitectura social y Estado..., opus cit., p, 122.

12 ANDRÉS EGUIBURU, Miriam, La reconstrucción de Gijón. La labor de la Dirección General de Regiones Devastadas, RIDEA, Oviedo, 2011, p. 42.

13 BOZAL, Valeriano, “Arte, ideología e identidad en los años del franquismo”. Ondare, 25, San Sebastián, 2006, p. 18.

14 CABRERA GARCÍA, María Isabel, "El pasado como condición: discurso artístico e identidad nacional durante el primer franquismo" en Restaurando la memoria (España e Italia ante la recuperación monumental de posguerra), Gijón, Trea, 2010, p. 47.

15 CABRERA GARCÍA, María Isabel, "El pasado...", opus cit., p. 47.

16 BOZAL, Valeriano, "Arte, ideología e identidad ...", opus cit., p. 18.

17 FLORES, Carlos, "La obra de Regiones Devastadas en el contexto de la arquitectura española contemporánea” en Arquitectura en Regiones Devastadas, MOPU, Madrid, 1987, p. 55. que España volviese a alcanzar el esplendor del pasado.

\subsection{El neoprerrománico asturiano como estilo dentro de la vertiente regionalista}

La recuperación de estos valores pasados desembocó en el rescate de los historicismos tanto en la arquitectura civil como en la religiosa, ambas útiles como medio de difusión de la "interpretación maniqueísta"18 de las consecuencias de la guerra. Sin embargo, en el ámbito religioso no sólo decidía el Estado sino que esta arquitectura también estuvo condicionada por los ideales de la propia Iglesia, de forma que los historicismos recuperados se correspondían con los estilos más representativos dentro de la historia del Cristianismo: el gótico y el barroco ${ }^{19}$, pues el país no sólo necesitaba una reconstrucción material, sino también una de cariz moral ${ }^{20}$ de la que se encargaría la Iglesia.

De cualquier manera, estos no fueron los únicos estilos desarrollados durante la posguerra, pues algunos teóricos apostaban también por el románico, por considerarlo un claro ejemplo de la unión Estado-Iglesia, tan claro durante el franquismo:

“El Románico es la arquitectura de ese nuevo imperio: La Cristiandad, presidido por el Papa y el Emperador. Es un sistema total y perfecto [...]"

$$
\text { Marqués de Lozoya }{ }^{21}
$$

No obstante debemos tener en cuenta que el interés por determinar e hispanizar la tradición

18 HERNÁNDEZ MARTÍNEZ, Ascensión, “Algunas reflexiones en torno a la restauración monumental en la España de posguerra: rupturas y continuidades", en Historia, restauración y reconstrucción monumental en la posguerra española, Madrid, Abada, 2012, p.107.

19 ANDRÉS EGUIBURU, Miriam, "La transformación de una imagen: la reconstrucción de la iglesia de San Pedro en Gijón”, en Liño, 16, Oviedo, 2010, p. 144.

20 ANDRÉS EGUIBURU, Miriam, "Imágenes de posguerra: adopciones y transformaciones en el paisaje asturiano" en La Albolafia: Revista de Humanidades y Cultura, 5, 2015, p. 91.

21 En palabras del Marqués de Lozoya: "El Románico es la arquitectura de ese nuevo imperio: La Cristiandad, presidido por el Papa y el Emperador. Es un sistema total y perfecto [...]”. Véase URÍA, Jorge, Cultura oficial e ideología en la Asturias franquista: el IDEA, Oviedo, Ethos, 1984, p. 107. 
del país ${ }^{22}$ hizo que la línea casticista o regionalista comenzase a cobrar gran relevancia en las formas constructivas de estos momentos, debido principalmente a dos motivos: la importancia del tradicionalismo y la situación económica que acabó por dar lugar a un "regionalismo productivo"23, basado en la utilización de los materiales y técnicas propios de cada región española.

Algunos ejemplos del uso de los regionalismos en distintas zonas de España los encontramos también en las reconstrucciones localidades de suma importancia simbólica en la época como Belchite o Brunete. Por un lado, sobre la posible viabilidad de reconstruir la primera en un estilo mudéjar, característico de Aragón, escribía Antonio Cámara en la revista Reconstrucción ${ }^{24}$; por otra parte, en el número 67 de esta misma publicación, se refleja el uso de los historicismos en los "cánones neoclásicos de Villanueva" en la iglesia de Brunete, aunque también "la esbelta interpretación de las (torres) que animaban la silueta madrileña" unida la presencia del típico chapitel de la arquitectura de la comunidad, en el campanario de la misma $^{25}$.

De esta manera, tampoco podemos pasar por alto otro de los regionalismos constructivos recuperados, concretamente en el caso Asturias: el prerrománico. Los motivos de su aceptación son sencillos, puesto que la ideología franquista se basaba, en gran medida, en el ideal de reconquista ${ }^{26}$ : la monarquía asturiana supuso el núcleo de resistencia a las invasiones musulmanas e inició el proceso que acabó con la recuperación de los territorios nacionales y la expansión del catolicismo de nuevo en época de los Reyes Católicos. Así, el Régimen y
Franco, más concretamente ${ }^{27}$, se identificaban con los monarcas asturianos estableciendo una sencilla analogía: el bando nacional recuperó también la patria y defendió al catolicismo de los ataques marxistas. La inclinación por la recuperación y reinterpretación de este estilo quedó patente también en escritos más teóricos como los realizados por Diego Reina de la Muela, quien manifestaba que "los balbuceos asturianos del siglo VIII [...] constituyen la primera expresión artística de tipo nacional e independiente" 28 .

Como resultado de todo esto, a lo largo de la geografía asturiana podemos observar de forma fehaciente cómo en la arquitectura de reconstrucción aparecen elementos neoprerrománicos tal como sucede en los casos de la iglesia parroquial de San Pedro de Gijón, donde la morfología del crucero, la rotundidad de los contrafuertes y las celosías evocan claramente el arte de la Monarquía Asturiana ${ }^{29}$. Además, en la cuenca del Nalón, lugar donde se habría ubicado el proyecto que comentaremos a continuación, se cuenta con varios ejemplos de la reinterpretación prerrománica de la posguerra como suponen la iglesia parroquial de San Andrés de El Entrego, cuya portada semeja la triple arcada de los miradores de Santa María del Naranco incluyendo los medallones como elemento decorativo; o la actual iglesia de San Pedro de La Felguera, que se comentará posteriormente.

Sin embargo, ningún templo realizado en Asturias supone un interés y una reinterpretación tan clara del prerrománico asturiano, como el proyecto realizado por Juan Ramón del Valle Lecue para la iglesia parroquial ubicada en La Felguera.

22 HERNÁNDEZ MARTÍNEZ, Ascensión, "Fernando Chueca Goitia y el arte mudéjar aragonés: arquitectura, historia y restauración. La intervención en la iglesia de San Félix de Torralba de Ribota (1953-1972)", en línea, http://www.revistadepatrimonio.es/revistas/numero 10/ intervencion/estudios2/articulo6.php

23 VÁZQUEZ DE CASTRO, Antonio, "Una experiencia arquitectónica en la dictadura” en Arquitectura en Regiones Devastadas, MOPU, Madrid, 1987, p.13.

24 FLORES, Carlos, “ La obra de Regiones Devastadas...”, opus cit., p. 56

25 ANÓNIMO, "Brunete", Reconstrucción, nº 67, Noviembre de 1946.

26 GARCÍA CUETOS, María Pilar, "Heritage and ideology. Monumental restoration and francoist sites of memory" en Heritage in conflict, Memory, History, Architecture, Aracne, Ariccia, 2015.

27 ANDRÉS EGUIBURU, Miriam, "Paisajes emblemáticos e identidad nacional: la reconstrucción de la Santa Cueva de Covadonga", en XVIII Congreso Español de Historia del Arte. Mirando a Clío. El arte español espejo de su historia, Santiago de Compostela, 2012, p. 2189.

28 ANDRÉS EGUIBURU, "Historicismos y regionalismos en la reconstrucción de posguerra: el Neoprerrománico Asturiano", en Artigrama, 25, 2010, p. 569.

29 ANDRÉS EGUIBURU, "Historicismos y regionalismos...", opus cit., p.575. 


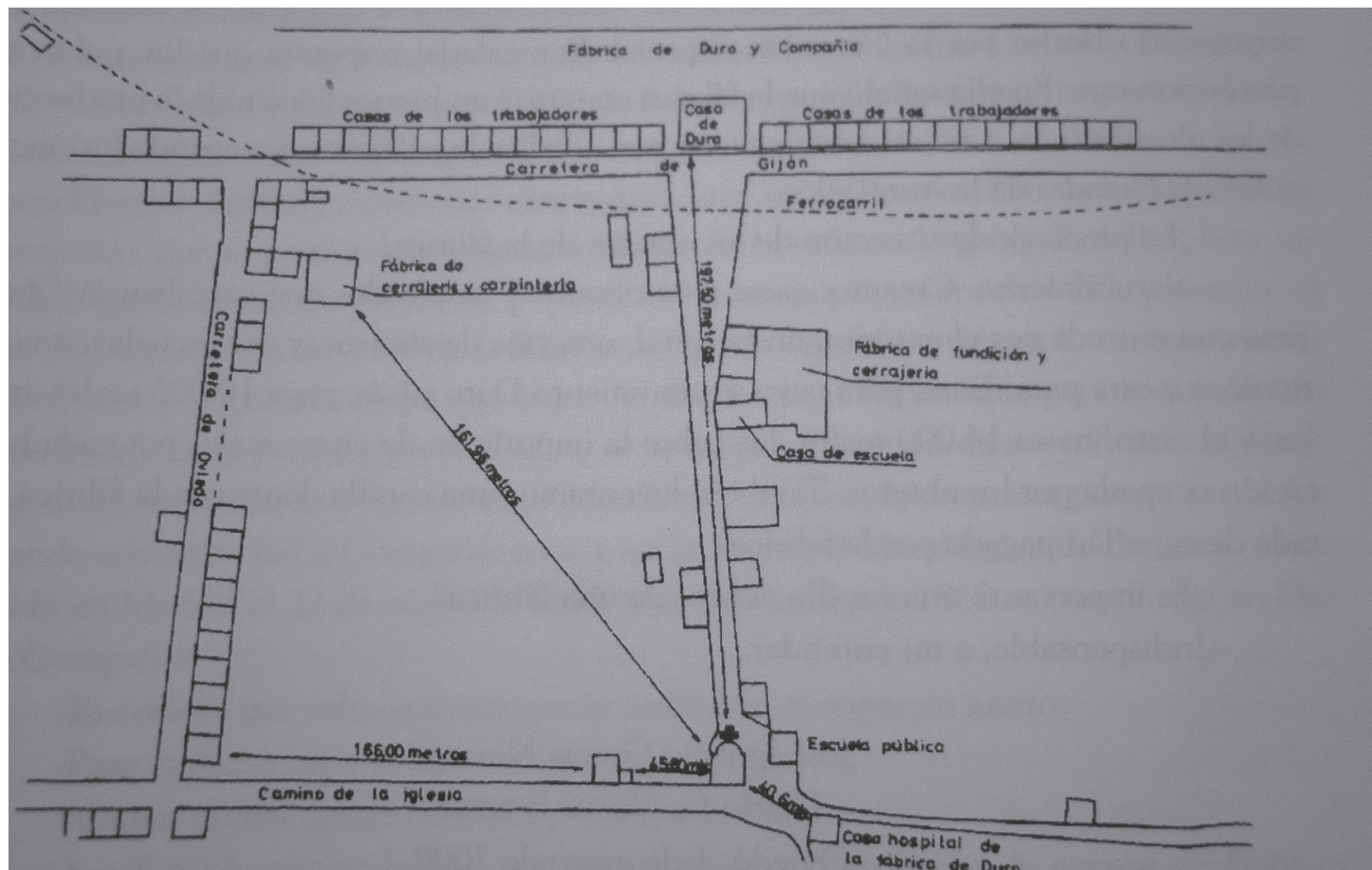

Fig. 1 Localización de la capilla de la Felguera en 1875. [Fuente: CABAL VIESCAS, José Arturo, Arte por Concejos en el Valle del Nalón. Oviedo. Obra social y cultural de Cajastur, 2002.]

\section{2.- La iglesia de San Pedro de La Felguera}

\subsection{Las primeras construcciones}

Turiellos, antigua denominación del actual distrito langreano de La Felguera, comenzó a experimentar un aumento demográfico y una incipiente urbanización gracias al asentamiento de la fábrica de Duro Felguera a finales del siglo XIX. Como consecuencia, se construyó una pequeña capilla de la que no se conservan apenas datos que, se supone, estuvo situada en las inmediaciones de la calle denominada " $\mathrm{Ca}$ mino de la Iglesia", como se puede observar en un plano de 1875 en el cual es identificable gracias a la cruz (Fig. 1).

No obstante, el constante aumento de la demografía, debido al auge de industrial de Langreo y la zona, desembocó en la necesidad de una nueva iglesia que permitiese albergar a toda la feligresía. Así, comenzó la construcción de un nuevo templo en la localidad, con la colaboración de todos sus habitantes, desde Pedro Duro y su yerno, Matías Fernández Bayo, hasta los propios feligreses ${ }^{30}$. El arquitecto diocesano Lucas María Palacios se encargó de las obras de

30 PLATERO, Ramón, Templos parroquiales construidos durante el pontificado de Fray Ramón Martínez Vigil, esta nueva iglesia, iniciadas en $1882^{31}$. El estilo elegido fue el historicista, contando el templo con tres naves, la central de mayor altura, pórticos a los laterales y una fachada de inspiración neorrománica en el cuerpo central, el cual estaba flanqueado por dos torres, rematadas por cúpulas de cuatro plementos, en las que se observaban dos tipos de vanos: abocinados, de inspiración románica, y geminados, más similares a los prerrománicos.

El día 7 de junio de 1885 se procedió a la inauguración de la iglesia parroquial de Santa Eulalia de Turiellos ${ }^{32}$, la cual sufrió varias reformas en los años posteriores, siendo sustituidas sus cúpulas por chapiteles octogonales, a comienzos del siglo XX, de forma que la configuración de la fachada se transformó totalmente.

La Revolución de Octubre y, finalmente, la Guerra Civil supusieron la destrucción completa de este templo por lo que la población de La Felguera, ante la necesidad de un lugar donde

O. P. (1884-1904), Oviedo, Real Instituto de Estudios Asturianos, 2005, p. 116.

31 PLATERO, Ramón, Templos parroquiales..., opus cit., p.116.

32 PLATERO, Ramón, Templos parroquiales..., opus cit., p.117. 


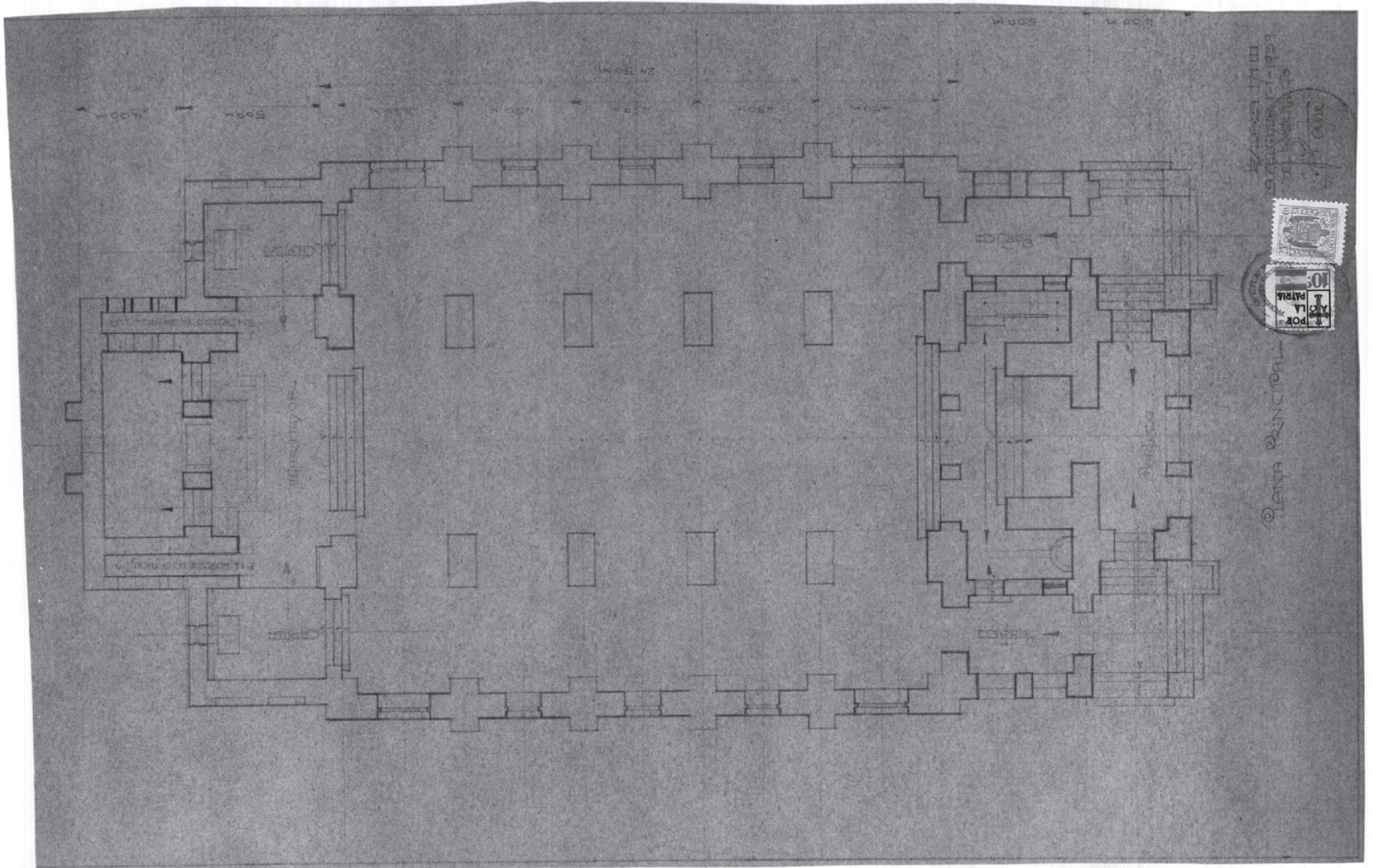

Fig. 2 Planta del templo [Fuente: Archivo General de la Administración, Fondo de la Dirección General de Regiones Devastadas, caja 3941, carpeta 1, Memoria constructiva, planos]

celebrar el culto, eligió un antiguo cine $^{33}$. Sin embargo, tras el fin de la contienda, llegó el momento de llevar a cabo la construcción de un nuevo templo que acogiese a la feligresía.

\subsection{El primer proyecto de reconstrucción}

José Ramón del Valle Lecue, nacido en Langreo en el año 1892, fue arquitecto por la Escuela de Madrid titulándose en 1919. Después se trasladó a Huelva donde acabó desempeñando el cargo de arquitecto municipal ${ }^{34}$. Pocos años después, regresó a Asturias y fijó su residencia en el actual distrito de La Felguera y entre 1924 y 1931 ostentó el mismo cargo en Langreo.

Años más tarde, pasó a ocupar una plaza en el Catastro de Oviedo donde llegó a ser Arquitecto Jefe y teniendo a sus órdenes a arquitectos de la talla de Ignacio Álvarez Castelao hasta su jubilación en el año 1962. Durante sus

33 AA.VV.: Parroquia de San Pedro de La Felguera. Cincuentenario del templo 1954-2004, La Felguera, Gráficas Lux, 2004, p. 26.

34 ARANDA IRIARTE, Joaquín, Autores de arquitectura en Asturias, Madrid, Rigel, 2011, p. 335 últimos años residió en Gijón, lugar en el que fallecería en $1981^{35}$.

Su relación con la iglesia parroquial de La Felguera comenzó cuando, en noviembre de 1939, fue el encargado de llevar a cabo el peritaje de los daños ocasionados por la guerra ${ }^{36}$. Después de haber realizado el envío de la valoración a la Comisión de la Dirección General de Regiones Devastadas, el Presidente-delegado de la misma propuso la aprobación del expediente y la autorización necesaria para la ejecución de las obras y la concesión del auxilio económico necesario para la reconstrucción del templo a través del Obispado en el mes de diciembre del mismo año ${ }^{37}$.

La primera propuesta de proyecto para la reconstrucción del templo de Santa Eulalia de Turiellos fue también realizada por José Ramón del Valle, siendo mostrada la maqueta del pro-

35 ARANDA IRIARTE, Joaquín, Autores de arquitectura..., opus cit., p.335.

36 VALLE LECUE, José Ramón, Tasación perital de daños,1939. Archivo General de la Administración (en adelante, AGA), Fondo de la Dirección General de Regiones Devastadas, caja 3941, carpeta 1.

37 Informe-propuesta de la Comisión de la Primera Zona del Servicio Nacional de Regiones Devastadas, 1939. AGA, Fondo de la Dirección General de Regiones Devastadas, caja 3941, carpeta 1 . 
yecto en el álbum de las fiestas locales de San Pedro $1940^{38}$, y es indudable que el diseño encaja a la perfección con los ideales estético-artísticos del franquismo, dentro de la corriente casticista, ya que se basa en una clara recuperación de formas prerrománicas.

En la memoria del proyecto realizado por Valle Lecue, se afırma que se construiría la iglesia en el mismo solar sobre el que se asentaba el templo anterior, y que se aseguraría un tamaño y capacidad similares aprovechando los cimientos conservados. La planta diseñada (Fig. 2), simétrica y longitudinal, contaría con nártex, cuerpo de naves y cabecera. Estaría dividida en tres naves, siendo la central de mayor altura y luz, separadas por pilares de planta rectangular en los que se apoyaría la arquería y no contaría con crucero destacado en planta, aunque sí en el alzado exterior.

$\mathrm{Si}$ analizamos el alzado (Fig. 3), podemos observar cómo los cuerpos anterior y posterior de la nave central aparecen elevados sobre el nivel del suelo, ya que bajo ellos se ubicarían la cripta y la sacristía; además, a cada lado de la entrada principal se encontrarían el baptisterio y la escalera del coro con entrada independiente por los pórticos laterales.

No obstante, es atendiendo al alzado exterior (Fig. 4) como podemos comprender hasta qué punto el proyecto de Valle Lecue se corresponde con una plena conjunción de elementos neoprerrománicos basados en los monumentos más destacados de la Monarquía Asturiana.

Así, el muro testero del templo se muestra como resultado de la unión entre los esquemas estructurales de Santa María del Naranco y de San Miguel de Liño: la parte inferior sigue el modelo de los miradores de Santa María, en tanto en cuanto se constituye a partir de un basamento sobre el que se dispone una triple arcada, con el arco central ligeramente peraltado, sobre la cual encontramos dos medallones. El tramo superior, con el que se remata el ábside, presenta una imagen muy similar a la de los cuerpos salientes de las naves laterales conservados en San Miguel de Liño, manteniendo la estructura de vano con celosía bajo otro abierto.

Si proseguimos siguiendo el eje longitudinal, podemos observar un cuerpo transversal a la nave central, constituyendo el crucero, el cual nos remite a Santa María de Bendones. Según la memoria, las naves laterales acusarían al exterior cuatro cuerpos de mayor altura, cuya función sería la de contrarresto a los arcos más elevados de la nave central, a la cual darían luz en su parte alta ${ }^{39}$. Estos cuerpos presentan claras reminiscencias respecto al posible aspec-

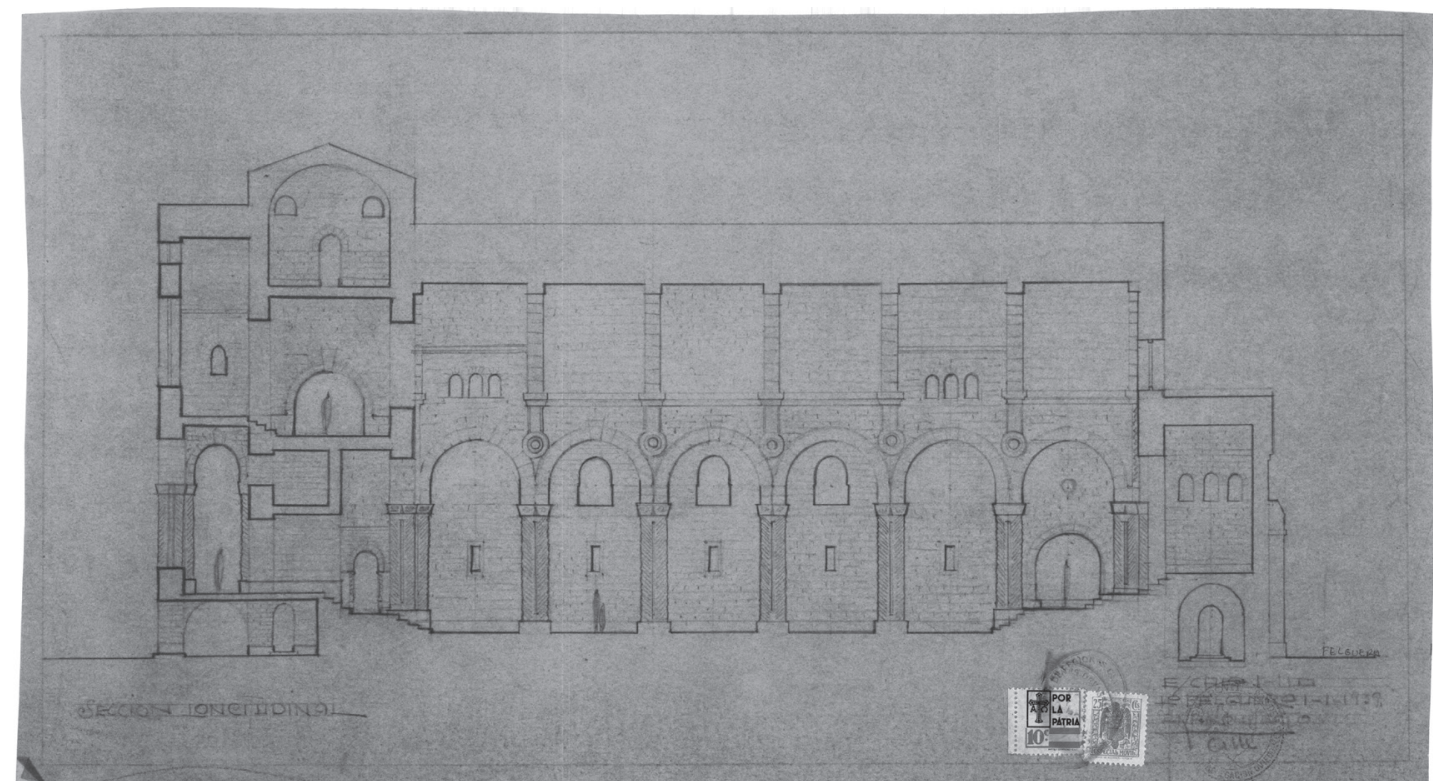

Fig. 3 Sección longitudinal de la iglesia [Fuente: AGA, Fondo de la Dirección General de Regiones Devastadas, caja 3941, carpeta 1, Memoria constructiva, planos]

$38 \quad$ AA.VV.: Parroquia de San Pedro de La Felguera..., opus cit., p. 26.
39 VALLE LECUE, José Ramón, Memoria del proyecto de Santa Eulalia de Turiellos, 1939. Fondo de la Dirección General de Regiones Devastadas, caja 3941, carpeta 1. 


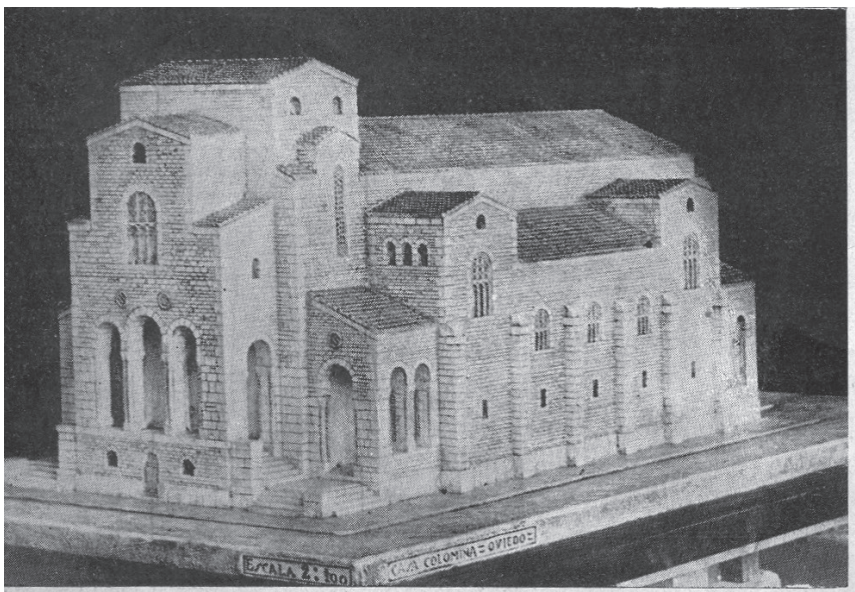

Maqueta del ante proyecto del nuevo TEMPLO PARROQUIAL de La Fel guera, del que es autor el arquitecto felguerino D. José Ramón Valle.

La arquitectura del bello edificio es de estilo ROMANICO-ASTUR, inspirada en algunas Iǵlesiąs Asturianas declaradas Monumentos Nacionales.

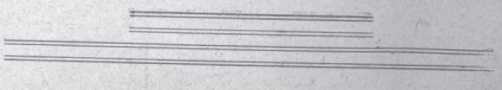

Fig. 4 Alzado exterior del templo, maqueta. [Fuente: AA.VV, Portfolio de las fiestas de San Pedro, La Felguera. Sociedad de Festejos, 1940.]

to original de San Miguel de Liño, con vanos cerrados por celosías y la sucesión de contrafuertes.

En cuanto a los materiales elegidos para la construcción del templo, destaca la idea de Valle Lecue de apostar por la piedra natural, a pesar de ser consciente de la carestía que tal decisión comportaba, ya que consideraba que "asegura la construcción de una perfecta conservación y aspecto estético de grandiosidad y riqueza, que está muy lejos de conseguirse con los procedimientos modernos de la piedra artificial $^{40}$. Sin embargo, para compensar el gasto que constituía el uso de la piedra natural en el exterior del templo, así como en solados, escalinatas y escaleras interiores y exteriores, el arquitecto decidió servirse de la piedra artificial en la parte decorativa interior y exterior en ventanas, columnas y arcos.

El diseño de Valle, a pesar de no haberse realizado, es un ejemplo indiscutible de la importancia de los regionalismos dentro de la arquitectura de posguerra. En este caso, la toma de modelos de los monumentos del Naranco, dos de los más representativos del arte de la Monarquía Asturiana, es una puesta en práctica del interés manifestado por el Régimen de establecer una analogía entre la arquitectura religiosa en estos momentos y la realizada por los monarcas asturianos.

40 VALLE LECUE, José Ramón, Memoria del proyecto de Santa Eulalia de Turiellos, 1939. Fondo de la Dirección General de Regiones Devastadas, caja 3941, carpeta 1.

\subsection{El proyecto definitivo}

No se conserva documentación en la que se manifieste claramente por qué el proyecto de Valle Lecue no llegó a realizarse, sin embargo las palabras de José Francisco de Zuvillaga y Zubillaga en la memoria de su proyecto para la reconstrucción del templo, que finalmente se construyó, pueden arrojar algo de luz al asunto:

"El anteproyecto cuyo estudio realicé anteriormente de acuerdo a los deseos manifestados por la Junta Parroquial a base de una sola nave de gran capacidad más las dependencias y servicios correspondientes, requería una superficie de terreno que si bien en un principio se creyó factible de conseguir, más tarde se vio la imposibilidad de llevarlo a la práctica". ${ }^{41}$

Zuvillaga decidió desechar el anteproyecto por considerarlo "francamente moderno consecuencia de la nave única de colosales dimensiones" 42 y optó por diseñar un templo, de carácter eminentemente neorrománico, que aprovechase los cimientos de la iglesia preexistente y cubriese las necesidades de capacidad, dependencias y servicios parroquiales.

${ }^{41}$ ZUVILLAGA Y ZUBILLAGA, José Francisco, Iglesia parroquial de La Felguera. Memoria descriptiva, hoja 1, 1941. Fondo de la Dirección General de Regiones Devastadas, caja 3941, carpeta 2.

42 ZUVILlagA Y ZUBILlAGA, José Francisco, Iglesia parroquial de La Felguera. Memoria descriptiva, hoja 1, 1941. Fondo de la Dirección General de Regiones Devastadas, caja 3941, carpeta 2. 


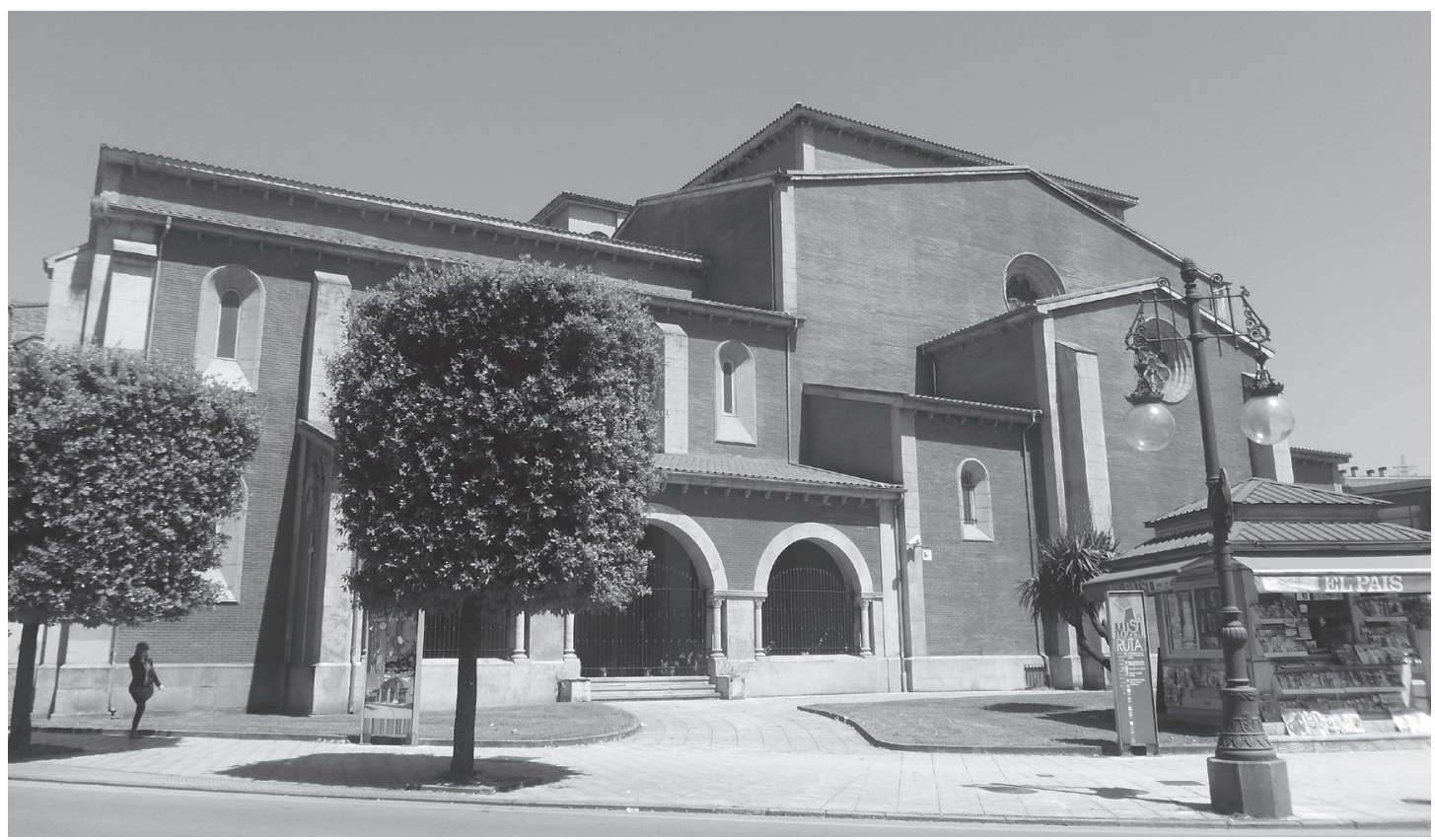

Fig. 5 Actual iglesia parroquial de San Pedro, La Felguera. [Fotografía de la autora]

El templo actual (Fig. 5) nada tiene que ver con el proyectado por Lecue, pues se articula a partir de una cuerpo dividido en tres naves que va a dar a un transepto de estructura octogonal, el cual precede un ábside de tramo recto. Sin embargo, a continuación se apuntarán brevemente todos los elementos en él presentes relacionadas con la utilización del regionalismo.

En primer lugar, la fachada se articula en tres cuerpos verticales, correspondientes con el cuerpo de tres naves que presenta el templo a sus pies, y que resulta muy similar a la configuración de la fachada de San Miguel de Liño, ya que la nave central aparece cubierta a dos aguas mientras que las laterales se cubren a una sola vertiente; además, la configuración del cuerpo principal mantiene tanto la presencia de la portada, aquí mucho más desarrollada y la presencia de un vano, en este caso un rosetón, que lo remata.

La cabecera se aleja de los esquemas románicos en tanto en cuanto reinterpreta un modelo indiscutiblemente prerrománico: presenta un muro testero recto que simula una división tripartita, debido a la disposición de vanos y contrafuertes, remitiendo claramente a la iglesia de Santullano o San Julián de los Prados. En la cabecera se repite la configuración de la fachada, ya que el espacio correspondiente a la nave central se desataca en altura y ampli- tud, además de aparecer cubierto a dos aguas, mientras que los de las laterales, que son más estrechos y de menor altura, están cubiertos a una sola vertiente. Cada espacio cuenta con la presencia de un vano y, en el cuerpo central se simula la denominada "cámara del tesoro", definida por la existencia de un vano trigeminado, en este caso cegado, sustentado por dos columnillas.

En el costado sur, siguiendo la tradición de algunas iglesias prerrománicas, aunque también románicas, nos encontramos con un pórtico, de nuevo reinterpretado, pues se compone mediante tres arcos de medio punto apoyados sobre pilares de gran tamaño.

La torre campanario, por su parte, no supone una reinterpretación neoprerrománica. No obstante, sí es muestra del regionalismo en tanto que su estructura, de sección cuadrada y 30 metros de altura, es muy similar a la de las torres románicas, siendo su precedente más claro la Torre Vieja de la Catedral de Oviedo. Esta similitud se observa, principalmente, en el remate cuyos muros perimetrales aparecen calados por dos vanos de arco de medio punto en cada uno. Las molduras del cuerpo de la torre son también de similares características, aunque en este caso, encontramos dos vanos en total, siendo uno de ellos de gran tamaño por lo que ilumina la mayor parte del cuerpo de la torre. 
En cuanto al interior, dos elementos resultan particularmente interesantes: el presbiterio, por su parte, aparece articulado en sus muros perimetrales a través de arquerías remitiendo de nuevo a la arquitectura prerrománica asturiana, en concreto, al ábside central de Santullano. Por otro lado, en los extremos del crucero encontramos, de nuevo, referencias al arte de la Monarquía Asturiana con la aparición de tres arcos de medio punto simulando los miradores de Santa María del Naranco.

Sin embargo, no encontramos elementos regionalistas únicamente en la estructura de esta iglesia parroquial, sino también en la decoración de la misma. En el exterior, en la portada lateral se puede observar un tímpano cuya iconografía no se corresponde con la habitual, pues el Pantocrátor en la mandorla mística, en lugar de aparecer rodeado del tetramorfos, aparece flanqueado por dos de los símbolos más relevantes de la Monarquía Asturiana: la Cruz de la Victoria y la Cruz de los Ángeles.

En cuanto al interior, las pinturas que decoran el templo son obra del pintor asturiano Magín Berenguer, quien se sirvió de una ornamentación claramente influenciada por la pintura mural prerrománica ya que, como él mismo afırmó, ésta presentaba unos "motivos que únicamente tienen la misión de embellecer" junto a otros que "atienden, además, a razones simbólicas”43.

\section{Conclusiones}

El final de la Guerra Civil supuso el establecimiento de unos ideales teórico-estéticos dentro del nuevo régimen, especialmente destacables dentro del campo de la arquitectura, cuyo catalizador principal fueron los organismos estatales creados ex profeso tales como la Dirección General de Regiones Devastadas y la Junta Nacional de Reconstrucción de Templos Parroquiales. A partir de entonces, se comenzó a manifestar cierta unidad de estilo constituida primordialmente por la recuperación de los historicismos.

Para la arquitectura religiosa los historicismos considerados más adecuados fueron el gótico, el barroco y el románico. Sin embargo, al igual que sucedía con el resto de construcciones a nivel nacional, la línea casticista, es decir, regionalista, también supuso un punto teórico y práctico de vital importancia.

Por este motivo, además de encontrar iglesias parroquiales con ciertos elementos neoprerrománicos dentro del territorio del Principado de Asturias, también contamos con proyectos, tanto el primero como el definitivo de la iglesia de Santa Eulalia (actualmente bajo la advocación de San Pedro) en La Felguera, que son una muestra perfecta de los ideales de este momento, pues son un claro producto de una época y un contexto político e ideológico que marcaría España y, en este caso, Asturias durante los primeros años de la posguerra.

43 BERENGUER, Magín, Las pinturas murales de las iglesias asturianas, París, Éditions du Centre International d'Études Romanes, 1962, p. 5. 